\title{
SAUDE COLETIVA DE MULHERES E HOMENS TRANS NO BRASIL: uma proposta de política pública inclusiva.
}

\author{
Fabrício Veiga Costa ${ }^{1}$ \\ Graciane Rafisa Saliba ${ }^{2}$
}

\begin{abstract}
Resumo: Objetiva-se investigar os parâmetros teóricos hábeis ao planejamento e à execução de política pública de saúde coletiva destinada a mulheres e homens trans no Brasil. A escolha do tema se justifica em razão de sua relevância teórica, prática e atualidade, especialmente em razão da invisibilidade, marginalidade e exclusão desses sujeitos. O modelo de política pública no Estado Democrático de Direito tem como parâmetro a participação popular, e por meio da pesquisa bibliográfica e documental, análises críticas, teóricas, temáticas, interpretativas e comparativas, demonstrou-se a necessidade de criação de política pública de saúde que garanta um tratamento humanizado e digno.
\end{abstract}

Palavras-chave: Política Pública; Saúde Coletiva; Mulheres e Homens Trans; Direito Fundamental à Saúde; Estado Democrático de Direito.

\section{COLLECTIVE HEALTH FOR TRANS WOMEN AND MEN IN BRAZIL: an inclusive public policy proposal.}

ABSTRACT: The objective is to investigate the theoretical parameters capable of planning and executing public collective health policy aimed at trans women and men in Brazil. The choice of the theme is justified due to its theoretical, practical and current relevance, especially due to the invisibility, marginality and exclusion of these subjects. The public policy model in the Democratic State of Law has popular participation as a parameter, and through bibliographic and documentary research, critical, theoretical, thematic, interpretative and comparative analyzes, the need to create a public health policy that guarantee humanized and dignified treatment.

Keywords: Public policy; Collective Health; Trans Women and Men; Fundamental Right to Health; Democratic Rule of Law.

\section{Introduçãa}

O objetivo geral da pesquisa é propor um modelo de política pública de saúde coletiva destinada a homens e mulheres trans, evidenciando a importância dessa proposição como parâmetro para assegurar a dignidade humana, inclusão e igualdade às pessoas trans no

\footnotetext{
${ }^{1}$ Professor do Programa de Pós-Graduação Stricto Sensu em Proteção dos Direitos Fundamentais pela Universidade de Itaúna -MG-. Doutorado e Mestrado em Direito Processual (PUCMINAS). Pós-doutorado em Educação (UFMG). Rua da Capela, n. 18, Bairro Dom Bosco, município Pará de Minas -MG-, CEP 35.66.-351. E-mail: fvcufu@uol.com.br.

${ }^{2}$ Professora da graduação em Direito da Universidade de Itaúna. Doutora em Direito do Trabalho (PUCMINAS) e Mestrado em Direito Internacional (PUCMINAS). Pesquisadora e advogada. Rua da Capela, n. 18, Bairro Dom Bosco, município Pará de Minas -MG-, CEP 35.66.-351. E-mail: graciane@ gracianesaliba.com.br.
} 
Brasil. A justificativa da escolha do tema proposto decorre da sua relevância teórica, prática e atualidade, especialmente a necessidade de se pensar num modelo de política pública de saúde coletiva que atenda pontualmente as demandas específicas da população trans, como é o caso do uso do nome social em hospitais e clínicas médicas, cirurgia de mastectomia para homens trans, colocação de próteses de silicone em mulheres trans e até a implementação de um sistema composto por profissionais especializados no planejamento e na execução da terapia hormonal, de modo a preservar a dignidade humana e a integridade (física, moral e psicológica) desses sujeitos.

Inicialmente será desenvolvido um estudo sobre o fenômeno social da transexualidade, vista como uma forma legitima de ruptura com o binarismo, cujo propósito é o reconhecimento da igualdade e dignidade mediante a proteção da identidade de gênero das pessoas trans. O direito fundamental à saúde é um desdobramento lógico-interpretativo da aplicabilidade e concretude do princípio da dignidade humana e do direito fundamental à vida, considerando-se que ter acesso à saúde é uma forma de proteger de forma ampla e integral a pessoa humana.

As políticas públicas no Estado Democrático de Direito tem o condão de assegurar às pessoas humanas a oportunidade de efetivarem os direitos fundamentais previstos no plano constituinte e instituinte, além de evidenciar a responsabilidade de cada ente estatal, dentro de suas esferas competenciais, de planejarem e executarem formas e métodos hábeis a garantir a igualdade no exercício desses direitos a todos os cidadãos. No momento em que o Estado se omite quanto à implementação de políticas públicas destinadas à garantia de oportunidade de exercício de direitos, legitima a exclusão, marginalidade e segregação de pessoas, reconhecendo sua inaptidão quanto ao gozo desses direitos considerados essenciais à proteção jurídica digna da pessoa humana.

Foi nesse contexto propositivo aqui apresentado que se delimitadou o objeto da pesquisa em tela, mediante a seguinte pergunta-problema: o planejamento e a execução de políticas públicas especificamente destinadas à saúde coletiva de mulheres e homens trans no Brasil constitui um meio legítimo de assegurar a dignidade humana e proteção do direito fundamental à saúde desses sujeitos de direito?

Por meio da pesquisa bibliográfica e documental, seguida da construção de análises temáticas, teóricas, interpretativas e comparativas foi possível demonstrar que a construção de políticas públicas destinadas especificamente à proteção da saúde coletiva de mulheres e 
homens trans no Brasil é uma forma de romper com a marginalidade e exclusão desses sujeitos, proporcionando maior igualdade e dignidade quanto ao exercício de direitos fundamentais básicos previstos no plano constitucional. A utilização do método dedutivo foi de significativa importância no recorte do objeto da pesquisa, partindo-se de uma concepção macroanalítica, qual seja, o estudo das políticas públicas no Estado Democrático de Direito, delimitando-se o espectro analítico no estudo específico das políticas públicas de saúde coletiva destinada a mulheres e homens trans no Brasil.

\section{Transexualidade, binarismo e identidade de gênero.}

O objetivo do presente item da pesquisa é apresentar a fundamentação teórica utilizada como referencial ao entendimento racional do tema transexualidade, correlacionando-o com as proposições decorrentes do binarismo e da heteronormatividade compulsória. Importante inicialmente esclarecer que o tema sexualidade proposto pela modernidade funda-se numa moldura que tem como parâmetro central os ideais taxonômicos propostos pelas ciências. Tanto a medicina quanto a ciência do direito adotaram metodologias a partir das quais a sexualidade, o sexo e os corpos das pessoas são classificados dentro de uma lógica dogmática. Ou seja, homem é o sujeito que tem pênis; mulher é o sujeito que tem vagina. Dessa forma, naturaliza-se a condição do homem e da mulher a partir de pressuposições genotípicas e fenotípicas.

Essas são as cognominadas caixinhas da sexualidade, criadas pela modernidade, com o objetivo de propor e impor padrões universais de como a sexualidade pasteurizada deve ser vivenciada pelas pessoas. Dentro dessa lógica, naturaliza-se, também, a heternormatividade compulsória, responsável por inserir a mulher numa posição de desigualdade estrutural perante o homem. Admite-se, nesse contexto, a relação heterossexual como o padrão de sexualidade adotado universalmente. O papel assumido pelo homem é o de reproduzir os ideais patriarcais, responsabilizando-se pela manutenção da mulher na posição de absoluta subserviência e desigualdade perante si.

As condutas que destoam dos padrões binário-heteronormativos impostos pela modernidade foram categorizados pela medicina como doença e pela ciência do Direito como crime. Em contrapartida a essas premissas tem-se os estudos de gênero e sexualidade propostos por concepções teóricas que rompem com esse dogmatismo analítico e, a partir 
disso, passam a compreender a sexualidade como "um estar", não mais como "um ser". Desse modo, a construção da identidade de gênero e da orientação sexual deixa de ser vista como algo natural, imposto cosmologicamente por premissas universais que independem da liberdade e da autonomia dos sujeitos. O "ser homem" e o "ser mulher" deixa de ser algo naturalizado pela genitália dos sujeitos e passa a ser visto como uma construção social, reflexo das experiências intersubjetivas.

Nesse sentido pode-se afirmar que essa nova concepção filosófica na forma de ver e compreender a sexualidade passa primeiramente pela ruptura do modus taxonômico responsável pela classificação de pessoas e de suas escolhas no âmbito sexual. Classificar pessoas como heterossexuais, homossexuais ou bissexuais constitui um meio de reproduzir vegetativamente as premissas trazidas pela modernidade. Romper com a categorização da forma como as pessoas vivem a sexualidade constitui um meio de reconhecer a liberdade e a autonomia dos sujeitos. Desconstruir os padrões modernos de sexualidade se torna necessário para o reconhecimento da diversidade e do pluralismo, características típicas da sociedade contemporânea. As formas de vivenciar a sexualidade e de cada sujeito construir sua identidade de gênero não cabem mais nas ditas "caixinhas" impostas pela medicina e pela ciência do Direito. A sexualidade é uma condição pluridimensional e dinâmica do sujeito, não caracterizada pela linearidade, visto que as vivências sexuais se dão de forma esférica, livres e desconstruídas (não naturalizadas) ao longo da vida.

O transexual é o sujeito que transgride e rompe com o binarismo, propõe uma nova forma de viver sua identidade de gênero, não mais naturalizado pela genitália. A pessoa trans permite-se ser o que subjetivamente sente ser. Por isso, constrói-se e se desconstrói ao longo de sua vida, ressemantizando algo que até então era visto como estático. A mulher trans constrói psicossocialmente sua identidade feminina, independentemente do seu órgão genital, algo que também ocorre com o homem trans, quando decide se construir com a identidade de gênero masculina. Não se pretende aqui compreender e nem esclarecer as razões dessas escolhas, haja vista que o objeto da presente pesquisa é o reconhecimento e tratamento igual conferido à pessoa humana, independentemente da forma como a mesma resolve vivenciar experiências subjetivas no âmbito de sua sexualidade.

Desconstruir as premissas dogmáticas de uma visão da sexualidade a partir da genitália é de fundamental importância para um debate crítico que ultrapassa os muros do dogmatismo. Não é o corpo do sujeito que desenha em si sua sexualidade, visto que nos 
dizeres de Simone Beauvouir "não é o corpo-objecto descrito pelos cientistas que exige concretamente, mas sim o corpo vivido pelo sujeito" (BEAUVOUIR, 2015, p. 81). A referida autora problematiza a condição da mulher, como um sujeito social, não mero reflexo de concepções naturalizadas, de uma ontologia que enrijece sua existência, ou seja, "não é a natureza que define a mulher: esta é que se define, retomando a natureza em sua afectividade" (BEAUVOUIR, 2015, p. 81). Nesse contexto, ninguém nasce mulher; torna-se mulher (BEAUVOIR, 2015), pois a condição do sujeito que se reconhece como mulher independe da existência do órgão sexual (vagina), já que tal condição é reflexo de questões psicossociais que se desenvolvem no âmbito da intersubjetividade e autodeterminação.

$\mathrm{Na}$ seara propositiva apresentada, faz-se necessário trazer os apontamentos teóricos propostos por Judith Butler: "concebida originalmente para questionar a formulação de que a biologia é o destino, a distinção entre sexo e gênero atende à tese de que, por mais que o sexo pareça irretratável em termos biológicos, o gênero é culturalmente construído" (BUTLER, 2015, p. 25-26). Assim, “se o gênero são os significados culturais assumidos pelo corpo sexuado, não se pode dizer que ele decorra de um sexo desta ou daquela maneira" (BUTLER, 2015, p. 26). A partir das proposições ora expostas, "a identidade de gênero se estabeleceria por meio de uma recusa da perda, a qual se encontra criptografada no corpo e, com efeito, determina o corpo vivo versus o morto" (BUTLER, 2015, p. 124).

As proposições filosóficas apresentadas problematizam o debate acerca dos temas sexo anatômico e identidade de gênero. "A configuração social do masculino e do feminino ou a ritualização da interação entre sexos já não são expressões antropológicas de um substrato biológico, e sim invenções humanas impregnadas de subjetivismo voluntaristas e sujeitas a livre arbítrio" (VERO, 2016, p. 61). Fica evidente a partir das colocações apresentadas que a liberdade, a autodeterminação e a autonomia privada do sujeito são conceitos fundamentais para tornar viável o entendimento crítico sobre as inúmeras identidades de gênero possíveis.

Partir do pressuposto de que os sujeitos são livres quanto às escolhas que poderão fazer no âmbito sexual, é o primeiro passo para a desconstrução de um modelo que aprioristicamente naturaliza a condição sexual de cada pessoa. Autodeterminar-se quanto às escolhas que cada pessoa poderá fazer ao longo da vida é reconhecer que a sexualidade é um “estar", não filosoficamente um "ser". Ao longo da vida cada sujeito tem autonomia para construir e desconstruir subjetivamente suas escolhas sexuais. Implica dizer que ninguém 
deve se reconhecer como homem ou mulher senão a partir de decisões que se dão no âmbito de sua subjetividade. Fatores psicossociais devem ser levados em consideração na construção da identidade de gênero de cada sujeito, como forma de assegurar sua dignidade humana. Nesse sentido, "não há, contudo, a pretensão de negar que o gênero se constitui com ou sobre corpos sexuados, ou seja, não é negada a biologia, mas enfatizada, deliberadamente, a construção social e histórica produzidas sobre as características biológicas" (LOURO, 2014, p. 25-26).

"A relação que normalmente se estabelece e se espera observar em todas as pessoas, é que corpos sexuados com pênis se identifiquem com o gênero masculino, assim como aqueles com vagina se reconheçam como femininos" (SANTOS, 2016, p. 109). Esse é o modelo de sexualidade construído pelas estruturas de poder na modernidade, avalizado pela medicina e endossado pela ciência do Direito. Endossar esse modelo de pensamento, além de representar uma forma de segregar pessoas em razão do desprestígio da diversidade, evidencia um modo de pensar cientificamente unilateral, já que muitos sujeitos são invizibilizados pelo simples fato de inexistirem dentro dessa proposta dogmática de enxergar a sexualidade humana. "Uma das consequências mais significativas da desconstrução dessa oposição binária reside na possibilidade que se abre para que se compreendam e incluam as diferentes formas de masculinidade e feminilidade que se constituem socialmente" (LOURO, 2014, p. 38). É nesse sentido que se torna relevante diferenciar racionalmente alguns conceitos científicos. $\mathrm{O}$ sexo é uma categoria conceitual que expõe as diferenças existentes quanto ao significado de ser fêmea e de ser macho, enquanto o gênero é proposição que se relaciona à construção social do que é ser mulher e homem, na perspectiva social e subjetiva. As diferenças sexuais do que é masculino e do que é feminino são vistas como representações sociais de identidades de gênero, e o entendimento de toda essa diversidade é fundamental para a construção do conceito de igualdade. Tais premissas deixam muito clara a importância da apreensão científica dos conceitos expostos, condição e requisito para o entendimento do tema igualdade de gênero.

É importante observar que no decorrer da história da humanidade "construiu-se uma concepção, a partir do pensamento binário, de que o gênero se definia a partir do sexo concebido biologicamente, marca expressivamente pautada pelas ciências biológicas - de perspectiva positivista- ao tentar definir os rumos e as verdades cabíveis à sociedade" (SEVERO, 2013, p. 61). Trata-se de proposições normativistas, fundadas em premissas 
construídas com o objetivo de estabelecer padrões universais de condutas, desconsiderando-se a pluralidade que marca os espaços sociais. No momento em que as ciências naturais sistematizaram na modernidade juízos apriorísticos e máximas generalizantes, objetivando estabelecer padrões universais de sexualidade, tornou-se inviável dar visibilidade à diversidade sexual, característica ínsita da sociedade civil contemporânea, marcada pelo pluralismo e pelas diferentes formas de viver. Nesse sentido, "os primeiros esforços de teorização sobre gênero versaram sobre a necessidade de diagnosticar as principais modalidades de sexismo operantes em sociedades contemporâneas" (LOPES, 2016, p. 21). Nesse contexto propositivo, "o gênero é concebido como construção social de papéis e desigualdades ancoradas no sexo, compreendido como fator biológico" (LOPES, 2016, p. 22). Assim, pode-se afirmar que "o gênero é compreendido como um revestimento social e cultural da diferença sexual” (LOPES, 2016, p. 22), diferença essa decorrente das inscrições universalizantes existentes nos corpos das pessoas, critério esse utilizado para classificá-las e gerar desigualdades no tratamento conferido aos sujeitos que livremente não aderem ao modelo binário-sexista imposto.

A compreensão cientifica dos debates existentes em torno da transexualidade é uma forma de desmitificá-la, utilizando-se de argumentos racionais como referenciais de desconstrução de crenças, dogmas e muito preconceito que permeia a temática. "Para compreendermos a transexualidade, é necessário entendermos que o sexo biológico e as características físicas não determinam a identidade sexual do indivíduo ou a percepção que este tem de si mesmo" (SAMPAIO; COELHO, 2012, p. 638). Na realidade, "a transexualidade tem se pautado num extenso debate político, social e intelectual e colocado em xeque, dentre outras, noções essencialistas sobre gênero, sexo, sexualidade e identidade" (PETRY; MEYER, 2011, p. 194). “As múltiplas maneiras de vivenciar a travestilidade e a transexualidade colocam em questão, mesmo que sem intenção, as normas de gênero que regem nossos conceitos de sexo, gênero e, no limite, de humano, explicitando a sua fluidez e a sua transitoriedade" (ALMEIDA; MURTA, 2013, p. 383).

O fenômeno psicossocial da transexualidade materializa no corpo das pessoas trans as ideias de que a biologia não é capaz de aprisionar o gênero, visto que se encontra desvinculado do sexo anatômico. "A transexualidade pode ser um desafio quando nos distanciamos da explicação reducionista de serem pessoas presas num corpo equivocado e compreendemos que são pessoas que combinam os conceitos de masculino e feminino, 
experimentando em graus diferenciados o nomadismo" (TEIXEIRA, 2012, p. 511). O transexual é o sujeito que vivencia ao longo da vida a experiência de pertencer ao sexo contrário ao que foi geneticamente concebido, compreendendo a sexualidade como um fenômeno psicossocial, e não como algo que foi naturalmente instituído no âmbito biológico. Esses sujeitos sentem-se livres a ponto de ousar querer construir uma identidade sexual distinta e diversa do que se encontra previamente posto.

\section{Direito fundamental à saúde como proposta de efetivação da dignidade humana.}

A saúde é um direito fundamental categorizado constitucionalmente como um direito social, previsto no caput do artigo 6 da Constituição brasileira de $1988^{3}$. O artigo 23 do texto constitucional prevê expressamente no inciso II que é competência comum da União, Estados, Distrito Federal e Municípios cuidar da saúde e assistência pública, bem como da proteção e garantia das pessoas com deficiência. Já o artigo 24, inciso XII, estabelece a competência concorrente da União, Estados e Distrito Federal legislar a defesa do direito fundamental à saúde. Aos municípios, conforme dispõe o artigo 30, inciso VII, compete prestar cooperação técnica e financeira à União e ao Estado no que atine aos serviços de atendimento à saúde da população. No mesmo sentido, o artigo 194, caput, prevê que a seguridade social compreende um conjunto integrado de ações de iniciativa dos poderes públicos e da sociedade, destinada a assegurar os direitos relativos à saúde, assim como a previdência e assistência social (BRASIL, Constituição brasileira de 1988).

Um dos dispositivos constitucionais mais importantes quanto ao tema em questão é o artigo 196, que é claro ao prever que a saúde é um direito de todos e dever do Estado, garantido mediante políticas sociais e econômicas que objetivem a redução do risco de doenças, devendo o Estado assegurar o acesso universal e igualitário das ações e serviços destinados à promoção e proteção da saúde (BRASIL, Constituição brasileira de 1988). Compreender a saúde como um direito social universal implica em entender suas duas vertentes, quais sejam, "uma de natureza negativa, que consiste no direito de exigir do Estado (ou de terceiros) que se abstenha de qualquer ato que prejudique a saúde" (SILVA, 2002, p.

\footnotetext{
${ }^{3}$ A consagração constitucional de um direito fundamental à saúde, juntamente com a positivação de uma série de outros direitos fundamentais sociais, certamente pode ser apontada como um dos principais avanços da Constituição da República Federativa do Brasil de 1988 (doravante designada CF), que a liga, nesse ponto, ao constitucionalismo de cunho democrático-social desenvolvido, sobretudo, a partir do pós-II Guerra. (SARLET; FIGUEIREDO, 2008).
} 
308). A outra vertente é "de natureza positiva, que significa o direito às medidas e prestações estaduais visando a prevenção das doenças e tratamento delas" (SILVA, 2002, p. 308). Nesse sentido, o poder público deverá regulamentar, fiscalizar e controlar a execução dos serviços e políticas públicas de saúde, ressaltando-se que tais ações são gerenciadas pelo Sistema Único de Saúde, cujas diretrizes constitucionais são as seguintes: a) descentralização dos serviços de saúde, com direção única em cada esfera de governo; b) atendimento integral, com prioridade para as atividades preventivas, sem prejuízo dos serviços assistenciais; c) participação da comunidade (artigo 197 - BRASIL, Constituição brasileira de 1988). Assim, pode-se afirmar que "a efetivação do direito à saúde pressupõe a articulação de uma rede regionalizada e descentralizada dos serviços de saúde, os quais devem ser regidos pelos princípios de universalidade, integralidade e igualdade, conforme previsto na legislação do SUS “ (RAPOSO, 2009, p. 121).

Conforme exposto, o direito à saúde encontra-se constitucionalmente previsto, seu acesso é universal e integral, devendo-se ponderar "que a implementação de políticas públicas se vincula a prestações materiais submetidas à dotação orçamentária dos entes federativos, bem como deve-se propiciar mais eficácia às decisões políticas, salvaguardando, primeiramente, as necessidades coletivas" (GONTIJO, 2010, p. 610). Novamente é importante destacar que a destinação das políticas públicas se encontra diretamente vinculada às necessidades coletivas, ou seja, será a apuração das demandas coletivas que condicionará o espectro da política de saúde pública a ser implementada.

A integralidade no acesso igualitário à saúde é uma conquista recente na história do direito brasileiro, até porque "a Constituição Federal de 1988 apresenta a integralidade pensada na lógica do acesso e articulação de todas as ações e níveis de atenção à saúde" (SILVA; BEZERRA; TANAKA, 2012, p. 252). Ou seja, "a integralidade compreende aspectos que envolvem desde a regulação das políticas públicas do setor ao olhar para o sujeito-usuário dentro de uma lógica de atendimento que considere o cuidado nas mais diversas dimensões do ser humano" (SILVA; BEZERRA; TANAKA, 2012, p. 252). A articulação de saberes, o compartilhamento de experiências, a atuação conjunta dos entes federativos dentro de um objetivo comum, são alguns fatores que contribuem significativamente para o resultado efetivo da política pública de saúde, que deverá levar em consideração as peculiaridades da microrregião onde será implementada. 
Nesse sentido, “dentro de um legítimo Estado Democrático de Direito, a saúde constitui-se como um direito público subjetivo, exigível contra o Estado, posto que seu exercício e efetividade dependem de aporte de recursos materiais e humanos a serem implementados por meio de políticas públicas de saúde" (BAHIA; ABUJAMRA, 2009, p. 303). A interpretação extensiva, sistemática, constitucionalizada e inclusiva do direito fundamental à saúde leva-nos a entender que o exercício pleno e integral desse direito exige do Estado uma postura positiva, ativa, no sentido de planejar e executar políticas públicas que permitam a todos o gozo do referido direito. Tais proposições decorrem do fato de o direito à saúde compreender "tanto o direito de estar sadio quanto o de ser tratado e se preparar para a vida profissional (habilitação e reabilitação) e o direito à prevenção de doenças (direito de permanecer sadio) pelo que as políticas públicas sanitárias merecem especial destaque" (BAHIA; ABUJAMRA, 2009, p. 303). Porém, “a efetivação do direito à saúde passa pela disponibilização de ações e serviços de natureza preventiva e curativa das doenças e outros agravos que prejudicam e põem em risco esse direito (BAHIA; ABUJAMRA, 2009, p. 303).

A saúde vista como um direito fundamental social possui estreita relação com outros direitos a ele correlatos, como é o caso da dignidade humana, igualdade e liberdade. Em razão das proposições aqui expostas constata-se que o direito à saúde "ao ser relacionado entre os direitos fundamentais, reconheceu-se a existência de situações objetivas e subjetivas, que passaram a ser definidas no direito positivo, em prol da dignidade, igualdade e liberdade da pessoa humana" (WERNER, 2008, p. 95). O objetivo do presente item da pesquisa é demonstrar que o direito à saúde se constitui num meio de tornar efetiva a dignidade humana das pessoas, mediante a implementação de políticas públicas voltadas à prevenção de doenças, orientação quanto ao uso de hormônios, assistência psicológica quanto ao entendimento da identidade de gênero, bem como outras demandas específicas da população trans.

O princípio da dignidade da pessoa humana ${ }^{4}$ encontra-se previsto no artigo 1 , inciso III do texto da Constituição brasileira de 1988, pois foi categorizado pelo legislador constituinte como um dos fundamentos da República Federativa do Brasil. Seu condão

\footnotetext{
4،[...] temos por dignidade da pessoa humana a qualidade intrínseca e distintiva de cada ser humano que o faz merecedor do mesmo respeito e consideração por parte do Estado e da comunidade, implicando, neste sentido, um complexo de direitos e deveres fundamentais que asseguram a pessoa tanto contra todo e qualquer ato de cunho degradante e desumano, como venham a lhe garantir as condições existenciais mínimas para uma vida saudável, além de propiciar e promover sua participação ativa e corresponsável nos destinos da própria existência e da vida em comunhão com os demais seres humanos" (SARLET, 2007, p. 62).
} 
principiológico decorre de sua natureza normativa, visto que traz em seu bojo um conteúdo aberto utilizado como referencial teórico para a interpretação e aplicabilidade de outros direitos fundamentais individuais e coletivos, como é o caso do direito fundamental à saúde. Nesse cenário é possível afirmar que a dignidade humana "concede unidade aos direitos e garantias fundamentais, sendo inerente às personalidades humanas" (MORAES, 2012, p. 19), tendo em vista que "esse fundamento afasta a ideia de predomínio das concepções transpessoalistas de Estado e Nação, em detrimento da liberdade individual" (MORAES, 2012, p. 19). Ou seja, “dignidade da pessoa humana é um valor supremo que atrai o conteúdo de todos os direitos fundamentais do homem, desde o direito à vida" (SILVA, 2002, p.105).

$\mathrm{O}$ advento da dignidade humana nos ordenamentos jurídicos em todo o mundo se justifica inicialmente pela ruptura com a concepção patrimonialista que regeu a ciência do Direito, essencialmente na vigência do Estado Liberal. Especialmente antes das duas primeiras guerras mundiais, privilegiava-se a proteção legal da propriedade privada, muitas vezes em detrimento da proteção integral da pessoa humana. Um exemplo no direito brasileiro de prevalência da proteção jurídica dos bens em detrimento da pessoa humana é o regime dotal de casamento, previsto nos artigos 278 a 288 do Código Civil brasileiro de 1916, que conferia ao pai o direito de pagar um dote (valor em dinheiro ou bens) para o homem que se casasse com sua filha. Com o advento da dignidade humana, a pessoa humana foi colocada como centro de proteção jurídica dos direitos, ressaltando-se que o papel assumido pela ciência jurídica passa a ser garantir ampla a integralmente o direito de todas as pessoas gozarem da proteção integral de sua vida humana, incluindo-se, nesse contexto, o acesso às políticas públicas de saúde coletiva.

" $\mathrm{Na}$ atualidade, a dignidade da pessoa humana constitui requisito essencial e inafastável da ordem jurídico-constitucional de qualquer Estado que se pretende Democrático de Direito" (BAHIA; ABUJAMRA, 2009, p. 297). Ou seja, todo ordenamento jurídico que adota como paradigma de Estado a democracia assume o compromisso com a dignidade humana, proteção ampla e integral dos sujeitos de direito, em seus espectros mais pontuais e específicos. É por isso que se torna relevante o planejamento e a executoriedade de políticas públicas construídas pelo Estado e com base nas premissas aqui expostas. Embora essas sejam as expectativas decorrentes do texto constitucional, "vinte anos após a promulgação da Constituição, presenciam-se, diariamente, situações em que a dignidade da pessoa humana é malferida" (BAHIA; ABUJAMRA, 2009, p. 298), ou seja, tal violação ocorre "não apenas 
pela violência direta em que há o repúdio da sociedade, mas, principalmente, pela formas veladas como o preconceito, o racismo e, acima de tudo, pela miséria em que vivem milhões de pessoas desprovidas das condições mínimas de sobrevivência” (BAHIA; ABUJAMRA, 2009, p. 298).

Debater o direito fundamental à saúde no contexto do princípio da dignidade da pessoa humana é reconhecer que "o direito à saúde constitui, sim, um direito subjetivo de cada indivíduo de exigir do Estado as medidas específicas para a preservação de sua saúde, e não somente aquelas que o Estado pretender prestar" (BRITO FILHO, 2013, p. 67). O respeito às diferenças e ao pluralismo (de ideias; concepções e visões de mundo); a superação da vertente patrimonialista, que privilegia a proteção da propriedade em detrimento da pessoa humana; a liberdade de escolha, materializada pelo exercício da autonomia privada; a igualdade de tratamento jurídico enquanto exercício dos direitos civis; a interpretação ampla, sistemática e inclusiva dos Direitos Fundamentais; o direito de não sofrer discriminação ou qualquer preconceito; o acesso às políticas públicas que assegurem de forma ampla o gozo dos direitos civis são algumas das propostas decorrentes do princípio da dignidade humana no Brasil. Garantir a dignidade humana às pessoas é um meio de descoisificá-las, assegurarlhes o exercício dos direitos expressamente previstos no plano constituinte e, acima de tudo, permitir o gozo e efetividade dos respectivos direitos fundamentais.

A saúde é considerada um direito fundamental social de natureza prestacional stricto sensu, cujo exercício se condiciona a uma postura positiva por parte do Estado em implementar políticas públicas que privilegiem as demandas sociais em cada microrregião especificamente. "Assegurar ao indivíduo, mediante a prestação de recursos materiais essenciais, uma existência digna é objetivo comum dos direitos fundamentais sociais, daí a íntima vinculação entre os direitos à saúde e o direito à vida, e ainda, o princípio da dignidade da pessoa humana" (RAMOS, 2003, p. 155). É nesse contexto propositivo que se pode afirmar que "os direitos sociais prestacionais têm por objeto uma conduta positiva por parte do Estado (ou particulares destinatários da norma), consistindo numa prestação fática" (GLOECKNER, 2013, p. 236), ou seja, "pressupõem a realização da igualdade material, garantindo a participação do povo na distribuição pública de bens materiais e imateriais para efetiva fruição das liberdades" (GLOECKNER, 2013, p. 236).

Numa outra perspectiva, a saúde pode ser vista como um direito da personalidade, mais especificamente como uma oportunidade de livre desenvolvimento da personalidade, 
haja vista se tratar de direito corolário da dignidade humana e da autonomia privada. Com relação especificamente ao objeto da presente pesquisa, a dimensão jurídica conferida à saúde implica no direito de escolher livremente a forma como cada sujeito construirá sua identidade de gênero, que no caso especificamente das pessoas trans, tal direito deve ser reflexo do livre desenvolvimento de sua personalidade. Ou seja, “o direito à dignidade da pessoa humana e o direito ao livre desenvolvimento da personalidade encontram-se positivados de forma expressa em diversos textos constitucionais europeus, especialmente nos ordenamentos jurídicos alemão, espanhol e português" (MARTINS; SAMPAIO JÙNIOR, 2012, p. 206). Verifica-se, assim, que "a proteção aos direitos à dignidade da pessoa humana e ao livre desenvolvimento da personalidade humana já se encontrava prevista no art. 22 da Declaração Universal dos Direitos do Homem (1948)" (MARTINS; SAMPAIO JÙNIOR, 2012, p. 206), tendo em vista que segundo o referido diploma normativo, "toda pessoa, como membro da sociedade, tem direito à realização dos direitos individuais, econômicos, sociais e culturais indispensáveis à sua dignidade e ao livre desenvolvimento da sua personalidade" (MARTINS; SAMPAIO JÙNIOR, 2012, p. 206).

Pensar a dignidade humana das pessoas trans, no contexto da constitucionalidade democrática, pressupõe o reconhecimento jurídico da igualdade e liberdade no que atine à construção da sua identidade de gênero. Para isso, torna-se relevante o planejamento e a execução de políticas públicas que garantam a visibilidade, a inclusão e a superação da marginalidade social, reflexo de uma sociedade sexista e transfóbica. O modelo de política pública de saúde coletiva destinada a mulheres e homens trans constitui um modo de garantirlhes dignidade, além de tornar concreto e efetivo os direitos fundamentais expressamente previstos no plano constituinte e instituinte.

\section{O papel das políticas públicas como instrumento de concretude dos direitos}

\section{fundamentais no Estado Democrático de Direito}

Políticas públicas são ofertas que devem ser feitas pelo Estado para tornar efetivamente viável e concreto os direitos civis considerados essenciais ao exercício digno e igual da condição de pessoa humana. O planejamento e a execução dessas medidas pelo Estado devem privilegiar todos os sujeitos que necessitam de meios para tornar viável o gozo daqueles direitos previstos no plano constitucional e infraconstitucional. 
A escolha de quais políticas públicas deverão ser implementadas deve ser reflexo de um estudo analítico das demandas existentes nos mais diversos setores da sociedade civil. $\mathrm{O}$ desenho de uma política pública passa inicialmente pela averiguação das demandas sociais, não podendo ser vista como mera decisão unilateral tomada pelo gestor. A gestão da coisa pública implica no compromisso com a coletividade, no seu mais amplo sentido, e, para isso, é essencial que suas proposições sejam extensíveis a todos os setores da sociedade civil, o que implica em considerar as minorias e sujeitos em situação de vulnerabilidade social.

Pensar numa política pública de saúde coletiva para mulheres e homens trans constitui um meio de exigir do poder público uma postura ativa no que atine à visibilidade desses sujeitos, permitindo-se que tenham acesso efetivo e igualitário a saúde pública de qualidade. Para isso, torna-se indispensável identificar as demandas da população trans quanto às questões relacionadas à terapia hormonal, acompanhamento psicológico para lidar com conflitos decorrentes da identidade de gênero e prevenção do autoextermínio, além de uma preparação especifica dos profissionais da saúde quanto ao acolhimento e o tratamento dispendido aos sujeitos trans.

É nesse contexto propositivo que se pretende problematizar o debate da política pública de saúde coletiva no Estado Democrático de Direito, uma forma de incluir pessoas como sujeitos que possam exercer direitos de maneira igual, permitindo-se concretizar os ideais estabelecidos no texto da Constituição brasileira de 1988.

A universalização dos direitos previstos no plano constituinte é o primeiro compromisso assumido pelo Estado e pelas instituições (públicas e privadas, como é o caso da família, escola, universidades e sociedade civil) em direção à igualdade no exercício desses direitos. De que vale um arcabouço legislativo minuciosamente descritivo, se o grande desafio enfrentado se refere à implementação desses direitos? O Estado Democrático de Direito precisa deixar de ser uma promessa restrita a literalidade dos textos legais para se concretizar no plano fático. É por isso que se faz relevante a utilização de políticas públicas como mecanismo de implementação dos direitos fundamentais. Assim, "para escaparmos da ilusão do Estado Democrático de Direito com suas práticas de resignação, a questão dos direitos deve ser colocada num "plano comum": direitos construídos na experiência concreta dos homens, de suas lutas e não do Homem idealizado, de direitos idealizados" (MONTEIRO; COIMBRA; MENDONÇA FILHO, 2006, p. 11). 
Pensar o direito enquanto ciência legitimada a assegurar proteção das pessoas não deve ser algo decorrente de juízos apriorísticos, máximas generalizantes fundadas em referenciais abstratos. Os direitos devem surgir das demandas e lutas da sociedade e de grupos minoritários e, nesse sentido, as políticas públicas devem ser compreendidas como uma forma de dar voz aos grupos minoritários e socialmente vulnerabilizados. Sistematizar as políticas públicas exclusivamente sob a ótica do gestor, sem permitir a participação dos seus destinatários na definição de suas premissas e objetivos, compromete os ideais democráticos de inclusão, visibilidade, igualdade e proteção integral das pessoas.

Uma política pública efetivamente democrática é aquela em que a investigação empírica é pressuposto lógico para seu planejamento e execução. É necessário compreender as peculiaridades do universo onde estão inseridos os destinatários dessas políticas públicas, antes mesmo de pensá-las e implementá-las. Somente assim se torna viável construir direitos voltados à proteção da diversidade e grupos minoritários.

O texto da Constituição brasileira de 1988 trouxe inúmeros direitos fundamentais que objetivam proteger ampla e integralmente todas as pessoas indistintamente. A forma de interpretação desses direitos deve levar em consideração o universo onde se encontram inseridos seus destinatários, rompendo-se com a visão abstrata de direitos criados sem uma finalidade específica, para implementar a visão concreta daqueles direitos voltados à proteção da diversidade e dos grupos minoritários. Nesse sentido pode-se afirmar que "o conteúdo dos direitos ganhou diversidade tanto em relação aos seus titulares (especificação subjetiva), substituindo o homem abstrato das primeiras declarações pelos homens e mulheres, homossexuais, negros, idosos e crianças, trabalhadores pobres [...] e minorias" (SAMPAIO, 2004, p. 245). Os direitos fundamentais no Estado Democrático de Direito materializam a "introdução de novas pretensões tuteladas [...], por exemplo, [...] a proibição de discriminações, [...] proteção contra a violência das mulheres e das crianças ou contra a mutilação genital" (SAMPAIO, 2004, p. 245). Observa-se, a partir dessas considerações, que a sistemática jurídica proposta pelo legislador constituinte se funda na premissa de que os direitos fundamentais devem ser vistos como referenciais teórico-legislativos de proteção da diversidade, conferindo a todos os sujeitos a visibilidade e o exercício daqueles direitos expressamente previstos no plano constituinte.

A importância dada aos direitos fundamentais está diretamente ligada às finalidades que os mesmos direitos têm numa ordem democrática, ou seja, "os direitos fundamentais são 
concebidos como direitos subjetivos de liberdades pertinentes ao titular perante o Estado, e, simultaneamente, como normas objetivas de princípios [...] e decisões axiológicas que possuem validade para todos os âmbitos jurídicos" (SOARES, 2000, p. 111). Dessa forma, "os direitos fundamentais, como resultado da personificação e positivação constitucional de determinados valores básicos [...], integram, ao lado dos princípios estruturais e organizacionais [...], a substância propriamente dita" (SARLET, 2004, p. 70), ou seja, “o núcleo substancial formado pelas decisões fundamentais, da ordem normativa, revelando que o mesmo num Estado constitucional democrático se tornam necessárias [...] certas vinculações de cunho material para fazer frente [...] à ditadura e ao totalitarismo" (SARLET, 2004, p. 70).

Foi nesse cenário que adveio o Estado Democrático de Direito, como proposição hábil a garantir às pessoas a dignidade, igualdade, proteção e gozo efetivo daqueles direitos civis expressamente previstos no plano legislativo. O Estado assume a responsabilidade de oferecer condições para que tais direitos se tornem efetivos, mediante a implementação de políticas públicas. É por isso que se pode afirmar que "o Estado Democrático de Direito distribui igualitariamente o poder e racionaliza-o, domesticando a violência, convertendo-se em império das leis no qual se organiza autonomamente a sociedade" (SOARES, 2000, p. 113). Os direitos fundamentais vinculam a atuação do gestor público, impossibilitando-o de agir conforme suas projeções pessoais, já que seu compromisso constitucional é fazer valer os direitos fundamentais, corolários do regime democrático. Nessa seara, as políticas públicas devem ser vistas como ferramentas utilizadas para dar voz às demandas coletivas, num estreito diálogo no qual seja possível apreender casuisticamente quais são os anseios de uma determinada sociedade no que atine à busca pelo exercício do que a lei assegura por si só.

Ouvir e considerar as vozes dos sujeitos sociais, como pressuposto para o planejamento das políticas públicas democráticas, é o que assegura sua legitimidade jurídica e efetividade. Por isso, "o pressuposto básico de um Estado Democrático de Direito é que os sujeitos do diálogo estejam no mesmo plano jurídico de argumentação e debate" (COSTA, 2016, p. 30), haja vista que "quando o Estado se coloca em posição superior aos sujeitos do diálogo, impondo soberanamente sua decisão, fica claramente comprometida a legitimidade democrática dos provimentos estatais" (COSTA, 2016, p. 30). As premissas lógicas que devem ser observadas em qualquer decisão tomada no âmbito de uma sociedade e regime democrático é que os destinatários do provimento final sejam seus reais e efetivos coautores. 
A inclusão dos sujeitos destinatários das políticas públicas em seu planejamento e execução constitui o meio jurídico mais adequado de garantir a legitimidade democrática das decisões estatais. Diz-se isso porque muitas vezes o olhar solitário e unilateral do Estado é insuficiente para identificar com clareza quais são as reais demandas pleiteadas por uma determinada sociedade civil. No momento em que tais destinatários são ouvidos torna-se possível perquirir com mais exatidão o que efetivamente aflige esses sujeitos, identificando-se quais bens jurídicos deverão ser priorizados no contexto da proteção jurídica buscada.

As políticas públicas no Estado Democrático de Direito representam o eixo para o exercício da cidadania. É por isso que "no plano democrático-constitucionalizado, as políticas públicas aparecem como exigências do cidadão à efetivação dos direitos fundamentalizados constitucionalmente, não como mera medida isolada praticada pelo Estado como desiderado de dar efetividade aos direitos fundamentais ou ao Estado Democrático de Direito" (PENNA, 2011, p. 211-212). Democracia e políticas públicas inclusivas são proposições teóricas que possuem estreito diálogo na esfera prática, até porque o ato político se materializa em ações destinadas à coletividade, a partir das demandas existentes. Desenhar de forma sistemática um modelo de fazer políticas públicas é uma tarefa que exige a participação popular, vista como um viés que permite ao gestor perquirir com maior exatidão quais são efetivamente os anseios sociais. No que atine especificamente ao direito fundamental à saúde, verifica-se que se trata de direito cujo exercício e implementação é condicionante da dignidade humana.

\section{Política pública de saúde coletiva para mulheres e homens trans no Brasil: proposições destinadas a inclusão e dignidade da população trans}

A efetividade do planejamento e execução de políticas públicas de saúde coletiva para a população trans exige, inicialmente, a participação direta de seus destinatários, como requisito de democraticidade da respectiva proposta. Além disso, torna-se indispensável conhecer o universo e a realidade vivenciada pelas pessoas trans, suas demandas, expectativas e necessidades. Tais colocações são relevantes para evidenciar que o papel dessa política pública é garantir a proteção do direito fundamental à identidade de gênero, visto como desdobramento lógico do princípio da não-discriminação, direito fundamental à liberdade e igualdade.

O direito de acesso à terapia hormonal com orientações técnico-cientificas específicas quanto à forma mais adequada de hormonização, seus benefícios e possíveis 
efeitos colaterais; o acolhimento e humanização no atendimento das pessoas trans no SUS Sistema Único de Saúde; acompanhamento psicológico e multidisciplinar por equipe multiprofissional; formação de profissionais para atuarem em núcleos especializado que consigam compreender e dimensionar a demandas específicas da população trans quanto ao acesso à saúde são as proposições iniciais para o desenho de uma política pública inclusiva, de acesso igualitário à saúde coletiva a travestis e transexuais.

Além disso, torna-se relevante destacar a necessidade de sistematizar um atendimento universal no SUS, que privilegie demandas específicas de cada seguimento existente dentro da comunidade trans; o respeito ao uso do nome social nos atendimentos de pessoas trans em redes de saúde pública ou privada (hospitais e clínicas), incluindo na ficha de atendimento do SUS um campo específico que possibilite que pessoas trans sejam tratadas pelo nome social; auxílio e apoio à família e maior conscientização das pessoas e da sociedade civil quanto às demandas e aos anseios da população trans; aprimoramento no atendimento no SUS, com maior agilidade e eficiência no tratamento digno e humanizado das pessoas trans; criação de curso de residência e formação especializada de médicos, enfermeiros e demais profissionais da saúde para lidarem com as demandas específicas do público trans são mais algumas proposições para o planejamento e a execução de uma política pública de saúde coletiva.

Outras questões essenciais para o modelo de política pública proposto dizem respeito às orientações específicas destinadas às mulheres trans, quanto à necessidade, riscos e consequências decorrentes da realização da cirurgia de redesignação sexual; orientações específicas para homens trans, no que diz respeito à cirurgia de mastectomia, realização de cirurgia ou utilização de prótese peniana e os possíveis desdobramentos na sua vida cotidiana, aspectos sociais e psíquicos; disponibilizar gratuitamente às mulheres trans oportunidade de colocação de próteses de silicone, tendo em vista que tal demanda não se restringe às questões estéticas, visto que integra uma das etapas para a construção da sua identidade de gênero. Propõe-se, ainda, como mais um desdobramento dessa política pública, a confecção de carteirinhas para os usuários trans do SUS (Sistema Único de Saúde), oportunizando o uso do nome social como medida hábil a oferecer um atendimento mais humanizado, acolhedor e digno a esses sujeitos.

\section{Conclusão}

Revista de Gênero, Sexualidade e Direito | e-ISSN: 2525-9849 | Encontro Virtual | v. 6 | n. 2 |

p. $01-22$ | Jul/Dez. 2020. 
A proposição teórica de um modelo de política pública destinada a homens e mulheres trans no Brasil constitui mais uma etapa da luta pela inclusão, igualdade, ruptura com as estruturas sociais do preconceito que se encontra naturalizado na sociedade brasileira. As primeiras premissas que regulamentam a efetividade das políticas públicas de saúde coletiva no Estado Democrático de Direito é a participação popular, mediante a oitiva das vozes dos destinatários da respectiva política, condição indispensável a sua democraticidade. Nesse sentido, a implementação do exercício efetivo do direito à saúde constitui um meio de assegurar o pleno gozo da dignidade humana. Voltar o olhar dos estudos propostos para as pessoas trans constitui um meio de tornar tais sujeitos visíveis, rompendo com os paradigmas de exclusão e marginalidade reproduzidos vegetativamente por uma sociedade que aplaude a desigualdade de gênero. O transexual rompe com o binarismo, ressaltando-se que o corpo trans é um ato político que nega a concepção de sexualidade construída a partir da genitália dos sujeitos. Na realidade, o direito fundamental à identidade de gênero é corolário da igualdade, liberdade, dignidade humana e não-discriminação.

Os critérios e fundamentos teóricos utilizados para o planejamento e a execução de uma política pública destinada a mulheres e homens trans no Brasil são, inicialmente, a compreensão das demandas específicas de seus destinatários. Por isso, como modelo de política pública de saúde coletiva no contexto dessa pesquisa, propõe-se: disponibilizar no SUS terapia hormonal gratuita, com orientações técnico-cientificas específicas quanto a forma mais adequada de hormonização; acolhimento humanizado das pessoas trans por equipe multiprofissional; criação de núcleos especializados para identificar demandas específicas da população trans; respeito ao nome social, mediante a inclusão de campo para mencioná-lo na ficha de atendimento do SUS, além da confecção de carteirinha de atendimento no SUS com o nome social; criação de cursos de residência e formação especializada de médicos, enfermeiros e demais profissionais de saúde que lidam com as demandas de saúde da população trans; orientação específica destinada às mulheres trans quanto à necessidade, riscos e consequências da realização da cirurgia de redesignação sexual; disponibilizar gratuitamente o acesso a próteses de silicone para que as mulheres trans concluam mais uma etapa importante de construção de sua identidade de gênero; oferecer atendimento e orientação especializada a homens trans, quanto à terapia hormonal e realização da cirurgia de mastectomia. 
A propositura do respectivo modelo de política pública constitui um meio de problematizar e demonstrar a invisibilidade da população trans perante o Estado, haja vista que tais sujeitos ainda continuam a margem do SUS, justamente por não terem acesso a uma política pública de acesso digno, igualitário e humanizado nas redes públicas de saúde.

\section{Referências}

ALMEIDA, Guilherme; MURTA, Daniela. Reflexões sobre a possibilidade da despatologização da transexualidade e a necessidade da assistência integral à saúde de transexuais no Brasil. Sexualidad, Salud y Sociedad . Revista Latinoamericana, n.14 . ago. 2013 . pp.380.407. Disponível em http://www.scielo.br/pdf/sess/n14/a17n14.pdf. Acesso em 19 set. 2020.

BAHIA, Cláudio José Amaral; ABUJAMRA, Ana Carolina Peduti. A JUSTICIABILIDADE DO DIREITO FUNDAMENTAL À SAÚDE: CONCRETIZAÇÃO DO PRÍNCÍPIO CONSTITUCIONAL DA DIGNIDADE DA PESSOA HUMANA. ARGUMENTUM Revista de Direito, n. 10, p. 295-318, 2009 - UNIMAR. Disponível em http://ojs.unimar.br/index.php/revistaargumentum/article/view/1045/626. Acesso em 19 set. 2020.

BEAUVOIR, Simone. O Segundo Sexo. v.1, Lisboa: Quetzal Editores, 2015.

BRASIL. Constituição brasileira de 1988. Disponível em http://www.planalto.gov.br/ccivil_03/constituicao/constituicao.htm. Acesso em 17 set. 2020.

BRITO FILHO, José Claudio Monteiro de. DIREITO FUNDAMENTAL À SAÚDE: PROPONDO UMA CONCEPÇÃO QUE RECONHEÇA O INDIVÍDUO COMO SEU DESTINATÁRIO. TEMAS ATUAIS DE DIREITO. Rio de Janeiro: GZ Editora, 2013. Disponível em http://rakuten.livrariacultura.com.br/imagem/capitulo/42144163.pdf\#page=69. Acesso em 19 jan. 2020.

BUTLER, Judith. PROBLEMAS DE GÊNERO - Feminismo e Subversão da Identidade. Rio de Janeiro: Civilização Brasileira, 2015.

MONTEIRO, Ana; COIMBRA, Cecília; MENDONÇA FILHO, Manoel. ESTADO DEMOCRÁTICO DE DIREITO E POLÍTICAS PÚBLICAS: ESTATAL É NECESSARIAMENTO PÚBLICO? Psicologia \& Sociedade, v.18, n.2, maio-ago., 2006, p. 7-12. Disponível em https://www.redalyc.org/pdf/3093/309326327002.pdf. Acesso em 15 set. 2020.

GLOECKNER, Joseane Ledebrum. A reserva do possível como limite à efetividade do direito fundamental à saúde. A\&C - R. de Dir. Administrativo \& Constitucional | Belo Horizonte, ano 13, n. 51, p. 233-250, jan.-mar. 2013. Disponível em http://www.revistaaec.com/index.php/revistaaec/article/view/150/270. Acesso em 19 jan. 2020. 
GONTIJO, Guilherme Dias. A judicialização do direito à saúde. Rev Med Minas Gerais, 2010; 20(4): 606-611. Disponível em

file://C:/Users/Fabricio/Downloads/v20n4a18\%20(1).pdf. Acesso em 17 set. 2020.

LOPES, Laís. O QUE É GÊNERO? GÊNERO, SEXUALIDADE E DIREITO - Uma Introdução. Organizadores: Marcelo Maciel Ramos; Pedro Augusto Gravatá Nicoli; Paula Rocha Gouvêa Brener. Belo Horizonte: Initia Via, 2016.

LOURO, Guacira Lopes. GÊNERO, SEXUALIDADE E DEUCAÇÃO - Uma perspectiva pós-estruturalista. 16.ed. Petrópolis: Vozes, 2014.

MARTINS, Thiago Penido; SAMPAIO JÚNIOR, Rodolpho Barreto. Hermenêutica constitucional comparada: a contribuição da aplicabilidade do direito ao livre desenvolvimento da personalidade no ordenamento jurídico brasileiro. Cadernos da Escola do Legislativo, v.14, n.22, 2012. Disponível em https://cadernosdolegislativo.almg.gov.br/seer/index.php/cadernos-ele/article/view/161/131. Acesso em 19 set. 2020.

PENNA, Saulo Versiani. CONTROLE E IMPLEMENTAÇÃO PROCESSUAL DE POLÍTICAS PÚBLICAS NO BRASIL. Belo Horizonte: Forum, 2011.

PETRY, Analídia Rodolpho; MEYER, Dagmar Elisabeth Estermann. Transexualidade e heteronormatividade: algumas questões para a pesquisa. Textos \& Contextos, Porto Alegre, v. 10, n. 1, p. 193 - 198, jan.-jul. 2011. Disponível em https://www.redalyc.org/pdf/3215/321527168015.pdf. Acesso em 22 set. 2020.

RAMOS, Marcelene Carvalho da Silva. O Direito Fundamental à Saúde na Perspectiva da Constituição Federal. A \& C R. de Dir. Administrativo e Constitucional, Belo Horizonte, ano 5, n. 22, p. 147-165, out./dez. 2003. Disponível em http://www.revistaaec.com/index.php/revistaaec/article/view/627/80. Acesso em 19 jan. 2020.

RAPOSO, Clarissa. A Política de Atenção Integral à Saúde do Adolescente e Jovem: uma perspectiva de garantia de direito à saúde? Revista da Faculdade de Serviço Social da Universidade do Estado do Rio de Janeiro. v.6 - Número 23 - jul. 2009. Disponível em https://www.e-publicacoes.uerj.br/index.php/revistaempauta/article/view/450/548. Acesso em 17 set. 2020.

SAMPAIO, José Adércio Leite. DIREITOS FUNDAMENTAIS. Belo Horizonte: Del Rey, 2004.

SAMPAIO, Liliana Lopes Pedral; COELHO, Maria Thereza Ávila Dantas. Transexualidade: aspectos psicológicos e novas demandas ao setor saúde. INTERFACE COMUNICAÇÃO SAÚDE EDUCAÇÃO v.16, n.42, p.637-49, jul.-set. 2012. Disponível em https://www.scielosp.org/article/icse/2012.v16n42/637-649/pt/. Acesso em 23 set. 2020.

SANTOS, Lohana Morelli Tanure. O QUE É TRANSEXUALIDADE? GÊNERO, SEXUALIDADE E DIREITO - Uma Introdução. Organizadores: Marcelo Maciel Ramos; Pedro Augusto Gravatá Nicoli; Paula Rocha Gouvêa Brener. Belo Horizonte: Initia Via, 2016.

SARLET, Ingo Wolfgang; FIGUEIREDO, Mariana Filchtiner. Algumas considerações sobre o direito fundamental à proteção e promoção da saúde aos 20 anos da Constituição Federal de 1988, 2008. Disponível em

http://www.stf.jus.br/arquivo/cms/processoAudienciaPublicaSaude/anexo/O_direito_a_saude _nos_20_anos_da_CF_coletanea_TAnia_10_04_09.pdf. Acesso em 17 set. 2020. 
SEVERO, Rafael Adriano de Oliveira. GÊNERO \& SEXUALIDADE - Grupos de Discussão como Possibilidade Formativa. Jundiaí: Paco Editorial, 2013.

SILVA, José Afonso da. CURSO DE DIREITO CONSTITUCIONAL POSITIVO. 21.ed. São Paulo: Malheiros, 2002.

SILVA, Keila Brito; BEZERRA, Adriana Falangola Benjamin; TANAKA, Oswaldo Yoshimi. Direito à saúde e integralidade: uma discussão sobre os desafios e caminhos para sua efetivação. INTERFACE COMUNICAÇÃO SAÚDE EDUCAÇÃO, v.16, n.40, p.24959, jan./mar. 2012. Disponível em https://www.scielosp.org/pdf/icse/2012.v16n40/249260/pt. Acesso em 17 set. 2020.

SOARES, Mário Lúcio Quintão. DIREITOS FUNDAMENTAIS E DIREITO

COMUNITÁRIO - Por uma metódica de direitos fundamentais aplicada às normas comunitárias. Belo Horizonte: Del Rey, 2000.

TEIXEIRA, Flávia do Bonsucesso. TÓRIAS QUE NÃO TÊM ERA UMA HISTÓRIAS QUE NÃO TÊM ERA UMA VEZ: AS (IN)CERTEZAS D AS (IN)CERTEZAS DA

TRANSEXUALID TRANSEXUALIDADE. Revista Estudos Feministas, Florianópolis, 20(2): 256, maio-agosto/2012. Disponível em http://www.scielo.br/scielo.php?pid=S0104026X2012000200011\&script=sci_arttext. Acesso em 19 set. 2020.

VERO, Justino. POR FALAR EM PRECONCEITO E GÊNERO... 1.ed. Rio de Janeiro: LMJ Mundo Jurídico, 2016.

WERNER, Patrícia Ulson Pizarro. O direito social e o direito público subjetivo à saúde - O desafio de compreender um direito com duas faces. Revista de Direito Sanitário, São Paulo, v.9, n.2, p. 92-131, jul-out., 2008. Disponível em

http://www.periodicos.usp.br/rdisan/article/view/13119/14922. Acesso em 17 set. 2020. 